\title{
THE VALUATION AND HEDGING OF VARIABLE RATE SAVINGS ACCOUNTS
}

\author{
BY
}

FRANK DE JONG ${ }^{1}$ AND JACCO WIELHOUWER ${ }^{2}$

\begin{abstract}
Variable rate savings accounts have two main features. The interest rate paid on the account is variable and deposits can be invested and withdrawn at any time. However, customer behaviour is not fully rational and withdrawals of balances are often performed with a delay. This paper focuses on measuring the interest rate risk of variable rate savings accounts on a value basis (duration) and analyzes the problem how to hedge these accounts. In order to model the embedded options and the customer behaviour we implement a partial adjustment specification. The interest rate policy of the bank is described in an errorcorrection model.
\end{abstract}

\section{KEYWORDS}

Term structure, duration, uncertain cash flow, variable rates of return JEL codes: C33, E43

\section{INTRODUCTION}

A major part of private savings is deposited in variable rate saving accounts, in the US also known as demand deposits. Typically, deposits can be invested and withdrawn at any time at no cost, which makes a savings account look similar to a money market account. However, the interest rate paid on savings accounts is often different from the money market rate. In Europe, the interest rate paid on the savings account can actually be higher or lower than the money market rate. Even when these interest rates differ, depositors do not immediately withdraw their money from savings accounts when rates on

\footnotetext{
* We thank Dennis Bams, Joost Driessen, D. Wilkie, participants at the AFIR 2000 colloquium, and two anonymous referees for comments on previous versions of the paper. The usual disclaimer applies.

1 University of Amsterdam

2 ING Group and CentER, Tilburg University

ASTIN BULLETIN, Vol. 33, No. 2, 2003, pp. 383-397
} 
alternative investments are higher. Whatever the causes of this behaviour (market imperfections, transaction costs or other), these characteristics imply that the value of the savings accounts from the point of view of the issuing bank may be different from the nominal value of the deposits.

In the literature, the valuation of savings accounts is well studied. For example, Hutchison and Pennacchi (1996), Jarrow and Van Deventer (1998) and Selvaggio (1996) provide models for the valuation of such products. The first two papers build on the (extended) Vasicek (1977) model, whereas the latter paper uses a more traditional Net Present Value approach. In all these papers there is little explicit modeling of the dynamic evolution of the interest rate paid on the account and the balance, and how this evolution depends on changes in the term structure of market interest rates. For example, Jarrow and van Deventer's (1998) model is completely static in the sense that the interest rate paid on the account and the balance are linear functions of the current spot rate. In practice, it is well known that interest rates and balances are rather sluggish and often do not respond immediately to changes in the return on alternative investments, such as the money market rate. Typically, the interest rate paid on the account is set by the bank and the balance is determined by client behaviour. The balance depends, among other things, on the interest rate but also on the return on alternative investments. Because the paths of future interest rates and the adjustment of the balance determine the value of the savings accounts, an analysis of dynamic adjustment patterns is important.

In this paper, we analyze the valuation and hedging of savings deposits with an explicit model for the adjustment of interest rates and balances to changes in the money market rate. A recent paper by Janosi, Jarrow and Zullo (JJZ, 1999) presents an empirical analysis of the Jarrow and van Deventer (1998) model. They extend the static theoretical model to a dynamic empirical model, that takes the gradual adjustment of interest rates and balance into account. Our approach differs from the JJZ paper in several respects.

Firstly, we treat the term structure of discount rates as exogenous and calculate the value of the savings account by a simple Net Present Value equation. This approach, suggested by Selvaggio (1996) leads to simple valuation and duration formulas, and is applicable without assuming a particular term structure model. The drawback of the NPV approach is that we have to assume that the risk premium implicit in the discount factor is constant, but this may be a good first approximation because we want to concentrate on the effects of the dynamic adjustment of the interest rate paid on the account and balance and not on term structure effects.

Secondly, a difference between the JJZ model and ours is the modeling of the long run effects of discount rate shocks. In our model, there is a long run equilibrium, in which the difference between the interest rate paid on the account and the money market rate is constant, and the balance of the savings account is also constant (possibly around a trend). Short term deviations from these long run relations are corrected at a constant rate. This model structure is known in the empirical time series literature as an error correction 
model $^{3}$. This model has some attractive properties, such as convergence of the effects of shocks to a long-run mean.

The interest rate sensitivity is quantified in a duration measure. We demonstrate that the duration depends on the adjustment patterns of interest rate paid on the account and balance. We pay particular attention to the implications of the model for the hedging of interest rate risk on savings deposits. We illustrate how to fund the savings deposits by a mix of long and short instruments that matches the duration of the savings account's liabilities.

The paper is organized as follows. First the valuation of the savings accounts is dealt with in 2. In 3 the models on the pricing policy and the customer behaviour are presented, and a discrete time version of the model is estimated for the Dutch savings accounts market. 4 deals with the duration of this product and 5 with hedging decisions. The paper is concluded in 6 .

\section{VALUATION OF VARIABLE RATE SAVINGS ACCOUNTS}

The valuation problem of savings accounts and similar products was analyzed by Selvaggio (1996) and Jarrow and Van Deventer (1998). Their approach is to acknowledge that the liability of the bank equals the present value of future cash outflows (interest payments and changes in the balance). The present value of these flows does not necessarily equal the market value of the money deposited, and therefore the deposits may have some net asset value. Jarrow and Van Deventer (1998) treat the valuation of savings accounts in a no-arbitrage framework and derive the net asset value under a risk-neutral probability measure. However, in our paper we want to implement an empirical model for the savings rate and the balance, and therefore we need a valuation formula based on the empirical probability measure. We therefore adopt the approach proposed by Selvaggio (1996), who calculates the value of the liabilities as the expected present value of future cash flows, discounted at a discount rate which is equal to the risk free rate plus a risk premium ${ }^{4}$. Hence, the discount rate $R(t)$ can be written as

$$
R(t)=r(t)+\gamma,
$$

where $r(t)$ is the money market rate and $\gamma$ is the risk premium. We can interpret this discount rate as the hurdle rate of the investment, that incorporates the riskiness of the liabilities, as in a traditional Net Present Value calculation.

The main assumption in this paper is that this risk premium is constant over time and does not depend on the level of the money market rate. This assumption is obviously a simplification. Any underlying formal term structure model, such as the Ho and Lee (1984) model, implies that risk premia depend on the

\footnotetext{
3 We refer to Davidson et al. (1978) for an introduction to error correction models.

4 Selvaggio (1996) calls the risk premium the Option Adjusted Spread
} 
money market rate. However, the risk premia are typically small and since the focus of the paper is on modeling the dynamic adjustment of interest rates and balances, we ignore the variation in the risk premium and focus on the effect of shocks to the money market rate.

With this structure, the market value of liabilities is the expected discounted value of future cash outflows, i.e. interest payments on the account $i(t)$ and changes in the balance $D(t)^{5}$

$$
L_{D}(0)=\mathrm{E}\left[\int_{0}^{\infty} e^{-R s}\left[i(s) D(s)-D^{\prime}(s)\right] d s\right] .
$$

Notice that in this setup reinvestments of interest payments are counted as a part of deposit inflow $D^{\prime}(t)$. Working out the integral over $D^{\prime}(s)$ by partial integration we find that the value of the liabilities equals

$$
L_{D}(0)=\mathrm{E}\left[\int_{0}^{\infty} e^{-R s}[i(s)-R(s)] D(s) d s\right]+D(0) .
$$

Since the market value of the assets is equal to the initial balance, $D(0)$, the net asset value (i.e., the market value of the savings product from the point of view of the bank) is

$$
V_{D}(0)=D(0)-L_{D}(0)=\mathrm{E}\left[\int_{0}^{\infty} e^{-R s}[R(s)-i(s)] D(s) d s\right] .
$$

For an interpretation of this equation, notice that $R(t)-i(t)$ is the difference between the bank's discount rate and the interest paid on the account. Additional savings generate value with return $R(t)$. The costs of these additional savings are $i(t)$, however. The difference $R(t)-i(t)$ therefore can be interpreted as a profit margin.

The net asset value is simply the present value of future profits (balance times profit margin). Therefore, the net asset value is positive if the interest rate paid on the account is on average below the discount rate. Obviously, the net asset value is zero if the interest rate paid on the account always equals the discount rate.

As an example, consider the situation where the interest rate paid on the account is always equal to the discount rate minus a fixed margin, $i(t)=R(t)-\mu$, and the discount rate is constant over time. ${ }^{6}$ Moreover, assume that the balance is constant at the level $D^{*}$. In that case, the net asset value of the savings accounts is

$$
V_{D}^{*}=\frac{\mu}{R} D^{*}
$$

\footnotetext{
5 For notational clarity, the time variation in the discount rate $R$ is suppressed. If the discount rate is time varying, the exact expression for the discount factor is $e^{-\int_{0}^{\infty} R(u) d u}$.

6 This is a special case of the Jarrow and Van Deventer (1998) model.
} 
Intuitively, this is the value of a perpetuity with coupon rate $\mu$ and face value $D^{*}$. Figure 1 graphs the net asset value for different values of $R$ and $\mu$. For large profit margins and low discount rates, the net asset value can be a substantial fraction of the market value of the savings deposits.

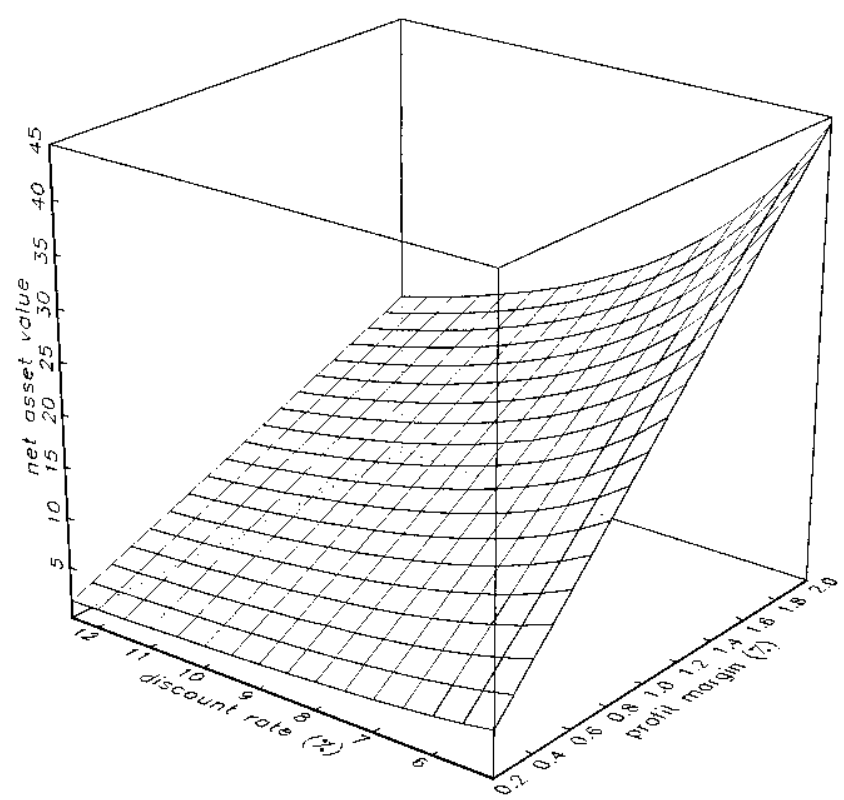

Figure 1: Net asset value

This figure shows the net asset value of a deposit of 100, as a function of the discount rate $R$ and the profit margin $\mu$

Obviously, this example describes the value in a static setting. For the interest rate sensitivity of the net asset value, we have to take into account that after a shock in interest rates, the interest rate paid on the account and the balance only gradually adjust to their new equilibrium values. In the next section we therefore present a model for the adjustment patterns of interest rate and balance after shocks to the discount rate. In the subsequent section we present discount rate sensitivity measures based on these adjustment patterns.

\section{Client and bank behaviour}

The analysis in the previous section shows that the net asset value of savings accounts depends on the specific pattern of the expected future interest rates and balances. The main difference between money market accounts and savings accounts is the sluggish adjustment of interest rates and balance to changes in the discount rate. In this section we model these adjustment processes. The 
models highlight the partial adjustment toward the long run equilibrium values of interest rates and balances. In the analysis, we take as given the path of the money market rate $r(t)$ and hence the path of the discount rate $R(t)=r(t)+\gamma$. We describe the stochastic evolution of the interest rate paid on savings deposits, $i(t)$, and the balance, $D(t)$, conditional on the path of the discount rate.

For the interest rate paid on savings accounts, we propose the following stochastic error correction specification

$$
d i(t)=\kappa[R(t)-\mu-i(t)] d t+\sigma_{1} d W_{1}(t)
$$

where $W_{1}(t)$ is a standard Brownian motion. This equation states that the interest rate adjusts to deviations between the long run value $R(t)-\mu$ and the current rate. We see this as the target policy rule of the bank that sets the interest rate. Deviations are corrected at speed $\kappa>0$, and in the long run, expected interest rates are a margin $\mu$ below the discount rate $R(t)$. The stochastic term $W_{1}(t)$ models the deviations from the target policy rule. Such deviations could be due to sudden demand shocks, competition from other banks and the like.

For the balance we propose a partial adjustment specification

$$
d D(t)=-\lambda\left[D(t)-D^{*}\right] d t-\eta[R(t)-\mu-i(t)] d t+\sigma_{2} d W_{2}(t)
$$

This specification has three components. Firstly, there is an autonomous convergence to a long run mean $D^{*}$, which is determined by a tradeoff by the clients between savings deposits and money market accounts. Secondly, there is an outflow of funds proportional to the excess of the discount rate over the savings rate. Thirdly, there is an unpredictable stochastic component.

This description with an autonomous convergence is especially suitable for a detrended time series. An autonomous convergence to a long run mean is expected in a detrended series for the balance. We detrend by defining the variable $D(t)$ as the fraction of total short term savings that is invested in variable rate savings accounts. In this case $D^{*}$ is the long run fraction of total short term savings that is invested in variable rate savings accounts. In this way, the trend growth of the total savings market doesn't affect the empirical estimation and the duration analysis.

Working out the stochastic differential equations (6) and (7) gives:

$$
\begin{aligned}
i(t)= & e^{-\kappa t} i(0)+\kappa \int_{0}^{t} e^{\kappa(s-t)}[R(s)-\mu] d s+\sigma_{2} \int_{0}^{t} e^{\kappa(s-t)} d W_{1}(s) \\
D(t)= & D^{*}+e^{-\lambda t}\left(D(0)-D^{*}\right)-\eta \int_{0}^{t} e^{\lambda(s-t)}[R(s)-\mu-i(s)] d s \\
& +\sigma \int_{0}^{t} e^{\lambda(s-t)} d W_{2}(s)
\end{aligned}
$$

To interpret these equations, let's consider the situation where the discount rate $R$ is constant over time. It is fairly easy to show that the effect of a 
change in the discount rate in this situation is given by the following partial derivatives

$$
\begin{aligned}
\frac{\partial i(t)}{\partial R}= & \kappa \int_{0}^{t} e^{\kappa(s-t)} d s=1-e^{-\kappa t} \\
\frac{\partial D(t)}{\partial R}= & -\eta \int_{0}^{t} e^{\lambda(s-t)}\left[1-\frac{\partial i(s)}{\partial R}\right] d s \\
& -\eta \int_{0}^{t} e^{\lambda(s-t)} e^{\kappa s} d s=-\eta\left(\frac{e^{-\lambda t}-e^{-\kappa t}}{\kappa-\lambda}\right) .
\end{aligned}
$$

The long run derivative of the interest rate paid on the account is one, but in the short run the effect is less than one. If $\eta>0$ and $\kappa>\lambda$ (which we show later is clearly the case empirically), the partial derivative of the balance is negative, and converges to zero in the long run.

These partial derivatives can be used to study the effects of a once-andfor-all shock to the discount rate, a kind of impulse response analysis. Starting from the equilibrium situation $D(0)=D^{*}$ and $i(0)=R-\mu$, the expected adjustment patterns are illustrated in Figure 2 for an increase in the discount rate by $1 \%$. The parameter values are picked from the empirical estimates to be discussed shortly, and are equal to $\kappa=0.79, \lambda=0.048$ and $\eta=0.43$ for the base case. We see that the interest rate doesn't follow the jump in the discount rate immediately but gradually adjusts to its new equilibrium value. The adjustment of the balance is more complex. Initially, the balance decreases because of withdrawals caused by the relatively low interest rate paid on the account. But as the interest rate increases, this effect becomes smaller and eventually the autonomous convergence of the balance to its long run level dominates. One interpretation of this is that clients who initially preferred the variable rate savings account to the money market account will return to variable rate savings accounts when the difference between the interest rate paid on the savings account and the money market rate reverts to the initial level.

Equations (9a) and (9b) also highlight the effects of the model parameters on the adjustment of interest rates and balance to a shock in the discount rate. The effect of $\eta$ is obvious, it increases the impact of an interest rate shock. This effect may be important in the current market, as the increase in the use of internet for banking services and the resulting lower transaction and search costs will probably increase the interest rate sensitivity of the customers. The effect of the mean-reversion parameters $\kappa$ and $\lambda$ is more complicated. A higher value of $\lambda$ speeds up the adjustment of the balance itself, but doesn't affect the interest rates. With a lower value of $\kappa$, both the adjustment of the interest rate and the balance are slower. The effect of the balance is a result of the dependence of the balance on the interest rate. These effects are illustrated in Figure 2, where the dashed line gives the adjustment pattern for a lower value of $\kappa$, and the dotted line the pattern with a higher value of $\lambda$. 

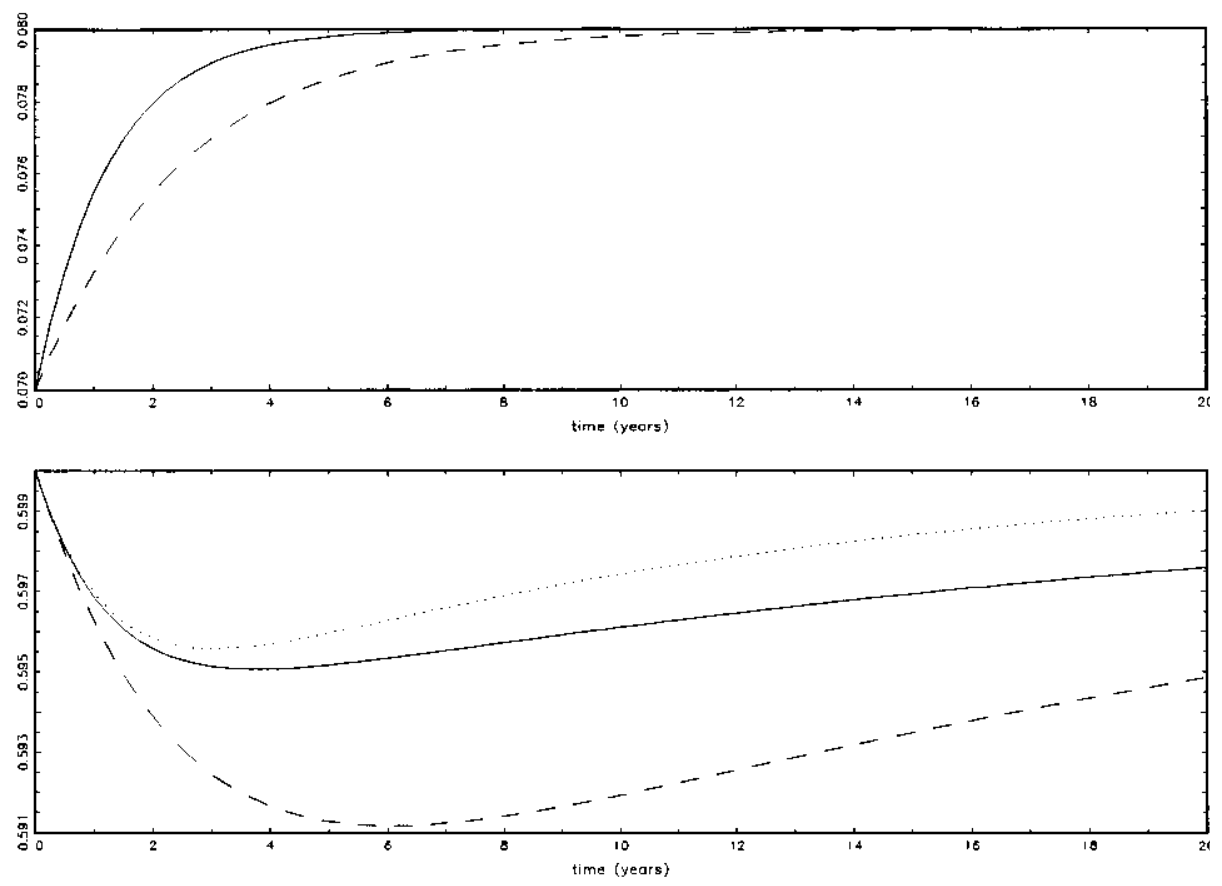

FIGURE 2: Adjustment of interest rate and balance of savings accounts

This figure shows the adjustment of interest rate (top panel) end balance (bottom panes) to a $1 \%$ shock in the discount rate. The solid line is the base case. The dashed line is for a smaller value of $\kappa$, the dotted line for a larger value of $\lambda$. The scale of the horizontal axis is years.

We now present some indicative estimates of the model parameters. This exercise is not meant to be a thorough empirical investigation of the adjustment pattern but merely serves as an illustration of the model. In order to translate the continuous time parameters to a discrete time setting, we use the following approximate ${ }^{7}$ discretization of the continuous time model

$$
\begin{aligned}
\Delta i_{t} & =\kappa\left[R_{t-1}-\mu-i_{t-1}\right] \Delta t+\epsilon_{1 t}, \\
\Delta D_{t} & =-\lambda\left(D_{t-1}-D^{*}\right) \Delta t-\eta\left[R_{t}-\mu-i_{t}\right] \Delta t+\epsilon_{2 t} .
\end{aligned}
$$

The discount rate is not directly observed in the data. Since a savings account shares characteristics of both a money market account and a long term deposit, its required rate of return (or discount rate) is proxied by a weighted average of the money market rate $\left(r_{t}\right)$ and the long term bond yield $\left(y_{t}\right){ }^{8}$

7 This approximation is quite accurate. For example, the exact mean reversion parameter for the interest rate equation is $1-\exp (-\kappa \Delta t)$, which for small values of $\kappa$ or $\Delta t$ is close to $\kappa \Delta t$.

8 An alternative but equivalent way to justify this proxy is to assume that the risk premium of the savings deposit is a fraction of the risk premium on long term bonds. 
We treat the weight $\delta$ as an unknown parameter which is estimated from the data. This leads to the following empirical model

$$
\begin{aligned}
\Delta i_{t} & =\alpha_{0}+\alpha_{1} \Delta r_{t}+\alpha_{2}\left[i_{t-1}-\left\{\delta r_{t-1}+(1-\delta) y_{t-1}\right\}\right]+e_{1, t}, \\
D_{t} & =\beta_{0}+\beta_{1} D_{t-1}+\beta_{2}\left[i_{t-1}-\left\{\delta r_{t-1}-(1-\delta) y_{t-1}\right\}\right]+e_{2, t} .
\end{aligned}
$$

This model is slightly more general than the theoretical model because it contains an immediate, discrete adjustment of the interest rate to the money market rate. After this initial jump, the adjustment to the new equilibrium is gradual. This effect turned out to be so important empirically that we included it in the empirical model..$^{9}$ The parameters of the continuous time model can be solved from the following equations (with $\Delta t=1 / 12$ for monthly data)

$$
\begin{aligned}
& \kappa=-\alpha_{2} / \Delta t, \\
& \lambda=\left(1-\beta_{1}\right) / \Delta t, \\
& \eta=\beta_{2} / \Delta t .
\end{aligned}
$$

In fact, the long run deposit level and the average spread of the interest rates over the estimated discount rate could be unraveled from the constant terms of the model. These are not very accurately estimated however and we refrain from drawing inferences about these parameters from the estimates.

We use monthly data on interest rates and deposits from the Dutch savings account market. The interest rate paid on the account is taken from one of the price setters in the Dutch market. The sample period is 1982:12 to 1999:12, spanning 17 years which is slightly longer than the samples of Hutchison and Pennacchi (1996) or JJZ. To remove trends in the total savings volume, we define the balance $D_{t}$ as the fraction of variable rate savings accounts to total savings. The following empirical estimates are obtained using least squares:

$$
\begin{aligned}
\Delta i_{t} & =-0.084+0.072 \Delta r_{t}-0.066\left[i_{t-1}-\left\{\delta r_{t-1}+(1-\delta) y_{t-1}\right\}\right]+e_{1, t}, \\
D_{t} & =0.21+0.996 D_{t-1}+0.039\left[i_{t-1}-\left\{\delta r_{t-1}+(1-\delta) y_{t-1}\right\}\right]+e_{2, t} .
\end{aligned}
$$

The estimate of $\delta$ is around 0.2 . These estimates imply the following annualized values for the continuous time parameters: $\kappa=0.79, \lambda=0.048$, and $\eta=0.43$. Using these parameters we can solve the second equation for the steady state value of the fraction of variable rate savings deposits to total savings, $D^{*}=0.58 .^{10}$

\footnotetext{
${ }^{9}$ Notice that including this term does not invalidate the duration analysis of the model, which is based on the gradual adjustment patterns only.

${ }^{10}$ The empirical average of $D_{t}$ is 0.51
} 


\section{Duration}

The previous section showed that the interest rate paid on the account and the balance of savings accounts are related to the discount rate. Therefore, the discount rate sensitivity of savings deposits will be different from the discount rate sensitivity of a money market account (which has a duration of zero). In this section, we study the sensitivity of the net asset value of a savings account to a parallel shift in the path of the discount rates. We study a shift from the original path $R(t)$ to $R(t)+\Delta R$, and evaluate the derivative in $\Delta R=0$. With some abuse of notation, we will write the resulting expressions as $\partial V / \partial R$ but it should be kept in mind that this refers to a parallel shift in the path of discount rates. This approach is close to a traditional duration analysis, see e.g. Bierwag (1987), but we take into account the dependence of future cash flows on discount rates.

In the initial situation, the deposits are at their equilibrium value $D^{*}$. Differentiation of the net asset value with respect the discount rate gives

$$
\begin{aligned}
\frac{\partial V_{D}(0)}{\partial R}= & \mathrm{E}\left[-\int_{0}^{\infty} s e^{-R s}[R(s)-i(s)] D(s) d s+\int_{0}^{\infty} e^{-R s} \frac{\partial[R(s)-i(s)]}{\partial R} D(s) d s\right. \\
& \left.+\int_{0}^{\infty} e^{-R s}[R(s)-i(s)] \frac{\partial D(s)}{\partial R} d s\right]
\end{aligned}
$$

The three components of this expression can be interpreted as follows:

1. the interest rate sensitivity of the expected discounted profits;

2. the change in the margin on the expected future balances;

3. the expected margin times increases or decreases in the balance of the deposit.

Notice that if the future balances do not change as a result of the interest rate change, and if the margin is constant, only the first term (the sensitivity of the present value of the profits) remains. The second and third term are specific for savings accounts with their slow adjustment of the interest rate and balance, and are therefore the most interesting for our analysis. We shall now discuss the duration of the accounts given the specific model for the evolution of interest rates and balances.

Assume again that $R(s)=R$ is constant, and that the initial situation is in equilibrium, $D(0)=D^{*}$ and $i(0)=R-\mu$. Under these initial conditions, the development of the interest rates and the balance can be derived from equations (8a) and (8b):

$$
\begin{aligned}
R-i(t) & =R-e^{-\kappa t} i(0)-\kappa \int_{0}^{t} e^{\kappa(s-t)}[R-\mu] d s-\sigma_{1} \int_{0}^{t} e^{\kappa(s-t)} d W_{1}(s) \\
& =\mu-\sigma_{1} \int_{0}^{t} e^{\kappa(s-t)} d W_{1}(s), \\
D(t) & =D^{*}+\eta \int_{0}^{t} e^{\lambda(s-t)}[R(s)-\mu-i(s)] d s+\sigma_{2} \int_{0}^{t} e^{\lambda(s-t)} d W_{2}(s) \\
& =D^{*}+\eta \sigma_{1} \int_{0}^{t} e^{\lambda(s-t)} \int_{0}^{s} e^{\kappa(u-s)} d W_{1}(u) d s+\sigma_{2} \int_{0}^{t} e^{\lambda(s-t)} d W_{2}(s) .
\end{aligned}
$$


Assuming that the stochastic parts of the interest rate and the balance are uncorrelated, i.e. $\operatorname{Cov}\left(d W_{1}(t), d W_{2}(t)\right)=0$, and noticing that the partial derivatives (9a) and (9b) are non-stochastic, we can work out the partial derivative of the value:

$$
\begin{aligned}
\frac{\partial V_{D}(0)}{\partial R}= & -\int_{0}^{\infty} s e^{-R s} \mathrm{E}\{[R-i(s)] D(s)\} d s \\
& +\int_{0}^{\infty} e^{-R s} \frac{\partial[R-i(s)]}{\partial R} \mathrm{E}[D(s)] d s+\int_{0}^{\infty} e^{-R s} \mathrm{E}[R-i(s)] \frac{\partial D(s)}{\partial R} d s \\
= & -\int_{0}^{\infty} s e^{-R s} \mu D^{*} d s+\int_{0}^{\infty} e^{-R s} e^{-\kappa s} D^{*} d s-\int_{0}^{\infty} e^{-R s} \mu \eta\left(\frac{e^{-\lambda t}-e^{-\kappa t}}{\kappa-\lambda}\right) d s \\
= & -\frac{\mu}{R^{2}} D(0)+\frac{1}{R+\kappa} D(0)-\frac{\eta \mu}{\kappa-\lambda}\left(\frac{1}{R+\lambda}-\frac{1}{R+\kappa}\right) .
\end{aligned}
$$

With an increase in the discount rate, the first term reflects the loss of value of the (perpetual) profit margin, the second term the discounted value of the interest payments not made on the original balance during the time the interest rate paid on the account $(i(t))$ is below the discount rate minus the profit margin $(R-\mu)$, and the third term the discounted value of the profit foregone on the balance outflows.

We can transform this change of value to a duration measure if we assume that initially, the net asset value equals $V_{D}(0)=D(0) \mu / R$

$$
\text { Dur }=-\frac{\partial V_{D}(0)}{\partial R} \frac{1}{V_{D}(0)}=\frac{1}{R}-\frac{1}{\mu} \frac{R}{R+\kappa}+\frac{\eta}{D(0)} \frac{1}{\kappa-\lambda}\left(\frac{R}{R+\lambda}-\frac{R}{R+\kappa}\right) .
$$

The first term reflects the duration of a perpetuity, and is determined by the present value of the profits in the steady state. The second term reflects the value of the lower interest rates paid on the existing balance, and is always negative. The third term is the duration of the profits on the additional balance outflows, and is positive under the assumption $\kappa>\lambda$. Especially when the margin $\mu$ is thin and the net asset value is low, the second term may dominate the other terms, leading to a negative duration for the net asset value of a savings account. In that case, an increase in the discount rate will increase the net asset value because for some time the interest rate paid on the savings account is lower than return on the assets deposited.

As an illustration Figure 3 shows the durations as a function of the discount rate $R$ and the margin $\mu$ (the other parameters are put equal to the estimates of the previous section). We see that the duration is typically positive, except for low values of $\mu$, and declines with the discount rate. Most of this effect is due to the duration of the discounted profit margin, $1 / R$. Leaving out this term, we find the 'extra' duration of the net asset value induced by the sluggish adjustment pattern. Figure 4 shows these measures. Interestingly, the 'extra' duration is always negative, but converges to zero for relatively big profit margins $\mu$. 


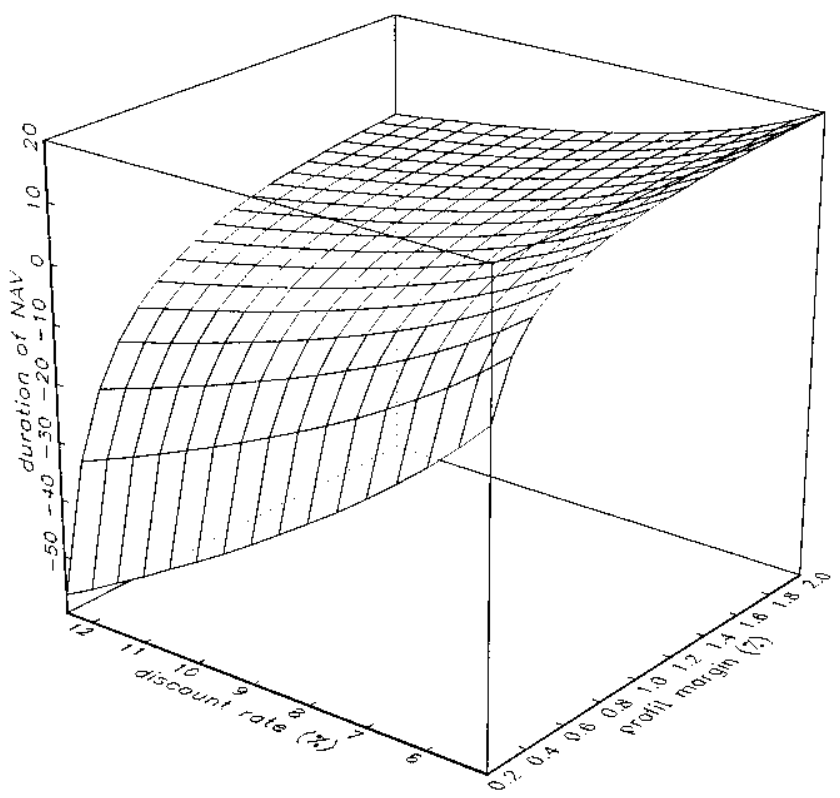

FIGURE 3: Duration of savings deposits

This figure shows the duration (in years) of savings deposits as a function of the discount rate $(R)$ and the profit margin $\mu$.

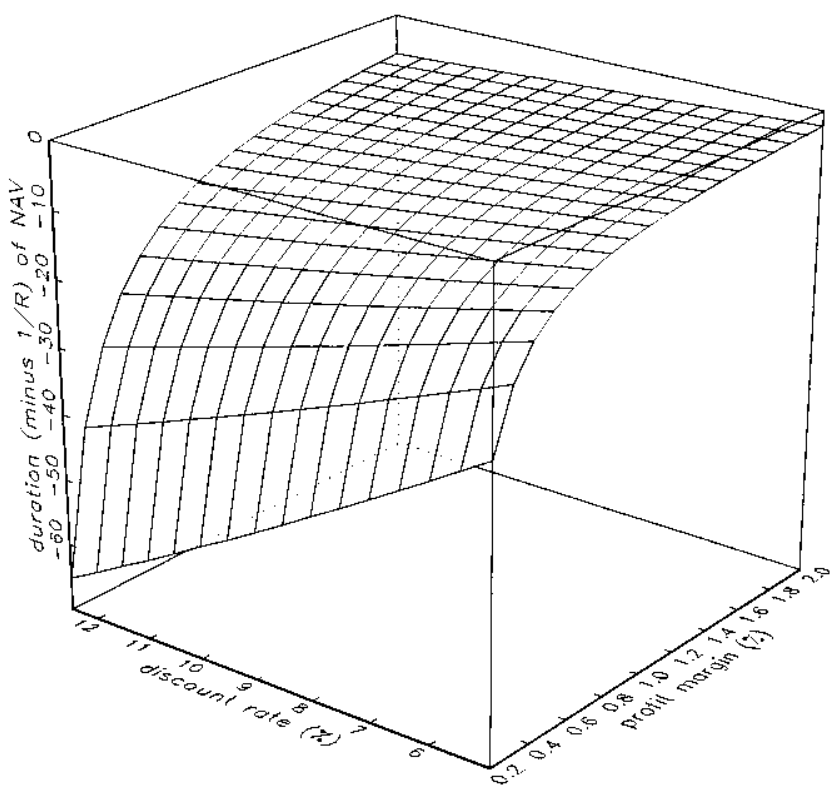

Figure 4: Duration of savings deposits (excluding profit margin)

This figure shows the extra duration (in years) of savings deposits, in excess of the duration of a perpetuity $(1 / R)$, as a function of the discount rate $(R)$ and the profit margin $\mu$. 


\section{HedGING}

In this section we consider the problem of hedging the net asset value. Given the liability value $L_{D}$ of the variable rate savings accounts, one can hedge the net asset value by immunization. For simplicity we assume the money deposited can be invested in two instruments, Long Investments $(L I)$ and Short Investments $(S I)$. The balance sheet of the bank then becomes

$$
\begin{array}{l|l}
\hline V_{L I} & L_{D} \\
V_{S I} & V_{D}
\end{array}
$$

where $V_{D}$ denotes the Net Asset Value. We now consider the construction of an investment portfolio where the interest rate risk on the net asset value is fully hedged, i.e. the net asset value $V_{D}$ is not sensitive to the parallel shifts in the discount rate. From the balance sheet we see that this requires

$$
\frac{\partial V_{S I}}{\partial R}+\frac{\partial V_{L I}}{\partial R}=\frac{\partial L_{D}}{\partial R} .
$$

Of course, the solution to this equation, and hence the composition of the investment portfolio, depends on the durations of the short and long investments. As a simple example, consider the case where the short instrument has zero duration. In that case the investment in the long instrument is determined by

$$
\frac{\partial V_{L I}}{\partial R}=\frac{\partial L_{D}}{\partial R} .
$$

We can find $\frac{\partial L_{D}}{\partial R}$ from equations (4) and (13).

As an illustration, Figure 5 graphs the required position in long (10 year maturity) bonds in the hedge portfolio for different value of $R$ and $\mu$. As seen before, the duration of variable rate savings accounts may be negative, in particular when the profit margin $\mu$ is fairly small. In that case the bank can hedge the accounts by taking a long position in long investments. But if Dur is positive, which happens for example when the profit margin $\mu$ is fairly high, one should take a short position in the long asset. Alternatively, if one does not like to take short positions in bonds, one could use derivative instruments such as caps, which typically have a negative duration, or forward contracts.

\section{CONCLUSION}

This paper focuses on the valuation and interest rate sensitivity of variable rate savings accounts. The duration can be split in three different effects:

- the duration of the expected discounted profits;

- the change in margin on expected future balances due to a change in interest rate;

- the expected margin times increases or decreases in the balance of the account. 


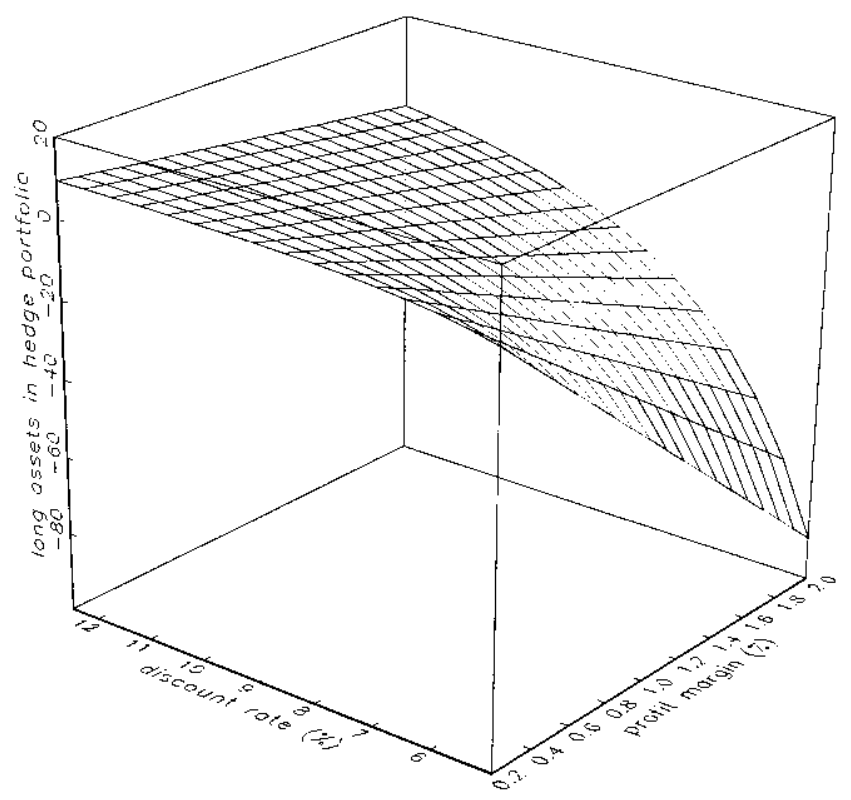

Figure 5: Hedge portfolio

This figure shows the position in long bonds (duration 10 years) in the hedge portfolio of a 100 deposit, as a function of the discount rate $R$ and the profit margin $\mu$.

The first element is the standard duration for products without embedded options. The second and third term are non-standard (for example, they are zero for a money market account) and arise due to the variable interest rate paid on the account and the option of the clients to withdraw and invest in the account at any time. The duration therefore crucially depends on the rapidness of the adjustment of the interest rate paid on the account to discount rate changes and on the reactions of the clients. These reactions will principally be determined by the clients interest rate sensitivity and by the market efficiency. The models are estimated for the Dutch savings account market. Duration curves are given for different margins.

When hedging the savings deposits, one can construct a portfolio with the same duration as the variable rate savings accounts. However, when one does not want to go short into a certain asset class, one might need to include derivatives (for example caps) to hedge these products, since it is possible to have negative durations. The intuition is that an interest rate increase might lead to a flight of clients to money market accounts. So buy 'insurance' when money market accounts are less attractive, which result in profits when interest rates spike up (the insurance pays out). The gain due to the caps in an increasing interest rate environment then offsets the loss in the savings accounts. Hedging in this way certainly smoothens the results on these products. Of course this can be achieved by going short in long assets as well. 
For future research it might be interesting to analyze the second order effects. Then multiple immunization can be achieved with a portfolio with three asset classes. Finally, it is possible to make the discount rate a function of a number of interest rates with different maturities. This will of course increase the complexity of the model but allows for the calculation of key-rate durations.

\section{REFERENCES}

BIERwag, G.O. (1987) Duration Analysis, Ballinger, Cambridge MA.

Davidson, J., Hendry, D.F., SRbA, F. and Yeo, S. (1978) Econometric Modelling of the Aggregate Time Series Relationship between Consumer' Expenditure and Income in the United Kingdom, Economic Journal, 88, 661-692.

Heath, D., Jarrow, R. and Morton, A. (1992) Bond pricing and the term structure of interest rates: A new methodology for contingent claims valuation, Econometrica 60, 77-106.

Ho, T.S.Y. and LeE, S.-B. (1986) Term structure movements and the pricing of interest rate contingent claims, Journal of Finance 41, 1011-1029.

Hull, J. (1993) Options, Futures and other Derivative Securities, second edition, Prentice-Hall.

Hutchison, D.E. and Pennacchi, G.G. (1996) Measuring Rents and Interest Rate Risk in Imperfect Financial Markets: The Case of Ratail Bank Deposits, Journal of Financial and Quantitative Analysis 31, 401-417.

JANOSI, T., JARROW, R. and Zullo, F. (1999) An Empirical Analysis of the Jarrow-van Deventer Model for Valuing Non-Maturity Demand Deposits, Journal of Derivatives, Fall 1999, 8-31.

JARROW, R.A., and VAN DEVENTER, D.R. (1998) The arbitarge-free valuation and hedging of savings accounts and credit card loans, Journal of Banking and Finance 22, 249-272.

SelvagGio, R.D. (1996) Using the OAS Methodology to Value and Hedge Commercial Bank Retail Demand Deposit Premiums, Chapter 12 363-373.

VASICEK, O. (1977) An equilibrium characterization of the term structure, Journal of Financial Economics 5, 177-188.

FRANK DE JONG

Finance Group

Universiteit van Amsterdam

Roetersstraat 11

1018 WB, Amsterdam

the Netherlands

Phone: +31-20-5255815

Fax: +31-20-5255285

Email: f.c.j.m.dejong@uva.nl 